\title{
Cement Augmentation in Sacroiliac Screw Fixation Offers Modest Biomechanical Advantages in a Cadaver Model
}

\author{
Georg Osterhoff MD, Andrew E. Dodd MD, FRCSC, Florence Unno MD, \\ Angus Wong, Shahram Amiri MSc, PhD, Kelly A. Lefaivre MD, MSc, FRCSC, \\ Pierre Guy MD, MBA, FRCSC
}

Received: 28 February 2016/ Accepted: 7 June 2016/Published online: 22 June 2016

(C) The Association of Bone and Joint Surgeons \& 2016

\begin{abstract}
Background Sacroiliac screw fixation in elderly patients with pelvic fractures is prone to failure owing to impaired bone quality. Cement augmentation has been proposed as a possible solution, because in other anatomic areas this has been shown to reduce screw loosening. However, to our knowledge, this has not been evaluated for sacroiliac screws.

Questions/purposes We investigated the potential biomechanical benefit of cement augmentation of sacroiliac screw fixation in a cadaver model of osteoporotic bone,

The institution of one of the authors (GO) received funding for this study from AO Trauma North America through a Fellowship Research Grant and by provision of implants from DePuy Synthes (Markham, ON, Canada).

All ICMJE Conflict of Interest Forms for authors and Clinical Orthopaedics and Related Research ${ }^{\mathbb{B}}$ editors and board members are on file with the publication and can be viewed on request.

Clinical Orthopaedics and Related Research ${ }^{\circledR}$ neither advocates nor endorses the use of any treatment, drug, or device. Readers are encouraged to always seek additional information, including FDAapproval status, of any drug or device prior to clinical use. Each author certifies that his or her institution approved the human protocol for this investigation, that all investigations were conducted in conformity with ethical principles of research, and that informed consent for participation in the study was obtained.
\end{abstract}

Electronic supplementary material The online version of this article (doi:10.1007/s11999-016-4934-9) contains supplementary material, which is available to authorized users.

G. Osterhoff ( $\square)$, A. E. Dodd, F. Unno, A. Wong, S. Amiri,

K. A. Lefaivre, P. Guy

Division of Orthopaedic Trauma, Department of Orthopaedics,

University of British Columbia, 3114-910 West 10th Avenue,

Vancouver, BC V5Z 1M9, Canada

e-mail: georg.osterhoff@usz.ch specifically with respect to screw loosening, construct survival, and fracture-site motion.

Methods Standardized complete sacral ala fractures with intact posterior ligaments in combination with ipsilateral upper and lower pubic rami fractures were created in osteoporotic cadaver pelves and stabilized by three fixation techniques: sacroiliac $(\mathrm{n}=5)$ with sacroiliac screws in $\mathrm{S} 1$ and $S 2$, cemented $(n=5)$ with addition of cement augmentation, and transsacral $(\mathrm{n}=5)$ with a single transsacral screw in S1. A cyclic loading protocol was applied with torque $(1.5 \mathrm{Nm})$ and increasing axial force $(250-750 \mathrm{~N})$. Screw loosening, construct survival, and sacral fracture-site motion were measured by optoelectric motion tracking. A sample-size calculation revealed five samples per group to be required to achieve a power of 0.80 to detect $50 \%$ reduction in screw loosening.

Results Screw motion in relation to the sacrum during loading with $250 \mathrm{~N} / 1.5 \mathrm{Nm}$ was not different among the three groups (sacroiliac: $1.2 \mathrm{~mm}$, range, $0.6-1.9$; cemented: $0.7 \mathrm{~mm}$, range, $0.5-1.3$; transsacral: $1.1 \mathrm{~mm}$, range, 0.6 2.3) $(\mathrm{p}=0.940)$. Screw subsidence was less in the cemented group (3.0 mm, range, 1.2-3.7) compared with the sacroiliac $(5.7 \mathrm{~mm}$, range, 4.7-10.4) or transsacral group $(5.6 \mathrm{~mm}$, range, $3.8-10.5)(\mathrm{p}=0.031)$. There was no difference with the numbers available in the median number of cycles needed until failure; this was 2921 cycles (range, 2586-5450) in the cemented group, 2570 cycles (range, 2500-5107) for the sacroiliac specimens, and 2578 cycles (range, 2540-2623) in the transsacral group ( $\mathrm{p}=$ 0.153 ). The cemented group absorbed more energy before failure $\left(8.2 \times 10^{5} \mathrm{~N}^{*}\right.$ cycles; range, $\left.6.6 \times 10^{5}-22.6 \times 10^{5}\right)$ compared with the transsacral group $\left(6.5 \times 10^{5} \mathrm{~N}^{*}\right.$ cycles; range, $\left.6.4 \times 10^{5}-6.7 \times 10^{5}\right)(\mathrm{p}=0.016)$. There was no difference with the numbers available in terms of fracture site motion (sacroiliac: $2.9 \mathrm{~mm}$, range, 0.7-5.4; cemented: 
$1.2 \mathrm{~mm}$, range, $0.6-1.9$; transsacral: $2.1 \mathrm{~mm}$, range, $1.2-$ 4.8). Probability values for all between-group comparisons were greater than 0.05 .

Conclusions The addition of cement to standard sacroiliac screw fixation seemed to change the mode and dynamics of failure in this cadaveric mechanical model. Although no advantages to cement were observed in terms of screw motion or cycles to failure among the different constructs, a cemented, two-screw sacroiliac screw construct resulted in less screw subsidence and greater energy absorbed to failure than an uncemented single transsacral screw.

Clinical Relevance In osteoporotic bone, the addition of cement to sacroiliac screw fixation might improve screw anchorage. However, larger mechanical studies using these findings as pilot data should be performed before applying these preliminary findings clinically.

\section{Introduction}

Fragility fractures of the pelvis are characterized mainly by disruption of the weakened bony structures with the ligaments remaining intact [36]. For this reason, most of these fractures can be treated nonoperatively with early full weightbearing mobilization [7]. Pelvic ring injuries with complete sacral fractures, however, are considered to be unstable and can benefit from early fixation [2, 13]. Operative treatment of these injuries also might accelerate mobilization and restoration of normal gait [34]. Osteoporotic lateral compression fractures with minimal displacement in the area of the anterior pelvic ring can be addressed specifically and successfully by percutaneous sacroiliac screw fixation [10, 23, 24, 31, 37, 42]. As these fractures most commonly affect older patients, any fixation technique should provide sufficient stability to allow for early full weightbearing.

In vitro, sacroiliac screws are able to restore greater than $80 \%$ of pretraumatic static stability of a vertical shear injury in pelves with normal bone stock [5]. In patients with osteoporotic bone, however, loosening of the screws frequently is seen [15, 30, 47]. This is a dynamic process and failure to achieve stable anchorage in sacroiliac screw fixation can result in loosening of the screws, but equally important can be the long-lasting immobilization resulting from pain in patients who are already-frail and deconditioned.

One option to increase fixation strength is the use of transsacral screws or bars $[15,17,24,25]$. Owing to variable morphologic features of the sacrum, however, a transverse transsacral corridor in S1 does not exist in at least $20 \%$ of individuals [26]. Therefore, some authors suggest the use of cement augmentation of the sacroiliac screw [19] because this has been proven to increase pullout strength of screws in other skeletal areas [21, 45] and the pelvis [16]. However, pullout strength is only an indirect measure of construct stability after pelvic fracture stabilization.

The purpose of this study was to investigate in vitro the potential biomechanical benefit of cement augmentation in sacroiliac screw fixation under conditions simulating cyclic loading of the pelvis. The underlying scientific question was whether cement augmentation in a cadaver model of osteoporotic bone improves the strength of the construct, specifically with respect to screw loosening, construct survival, and fracture-site motion.

\section{Material and Methods}

Fifteen fresh frozen osteoporotic cadaver pelves (median donor age, 83 years; range, 69-94 years) were used. Standardized left-sided complete sacral ala fractures with intact posterior ligaments in combination with ipsilateral upper and lower pubic rami fractures were created (Fig. 1), and the specimens were randomly assigned to one of three techniques of posterior pelvic ring fixation (Fig. 2).

In the sacroiliac group $(n=5)$, one cannulated screw (7.3 mm, fully threaded; DePuy Synthes, West Chester, PA, USA) with a washer was inserted through the ilium into each of the bodies of S1 and S2 using conventional Carm fluoroscopy as previously described [31].

In the cemented group $(n=5)$, sacroiliac screw fixation was performed as in the sacroiliac group. After placement of both screws, these were pulled back $25 \mathrm{~mm}$ and polymethylmethacrylate bone cement (3-4 mL; Simplex $\mathrm{P}^{\mathrm{TM}}$ Bone Cement; Stryker ${ }^{\circledR}$ Corporation, Kalamazoo, MI, USA) was injected through the screw's cannulated portion into the sacral body with a syringe. The screws then were immediately screwed in again and tightened before the cement cured. A backfill corridor of $25 \mathrm{~mm}$ was chosen for cement augmentation to be sure that the cement stayed in the S1 body and, thus, to avoid leakage into the fracture or the foramen.

In the transsacral group $(n=5)$, the same type of fullythreaded cannulated screws with washers was inserted across the bodies of S1 and S2 in a way that they reached the contralateral ilium. Fully threaded screws were used to avoid the threaded part to be a confounding factor depending on its position in the bone.

In all groups, the anterior part of the created pelvic ring fracture was stabilized by insertion of a retrograde transpubic screw [14].

Before group assignment, the bone mineral density (BMD) of all specimens was measured using quantitative CT. Scans were performed on a phantom (Model 3 Calibration Phantom; Mindways Software Inc, Austin, TX, 


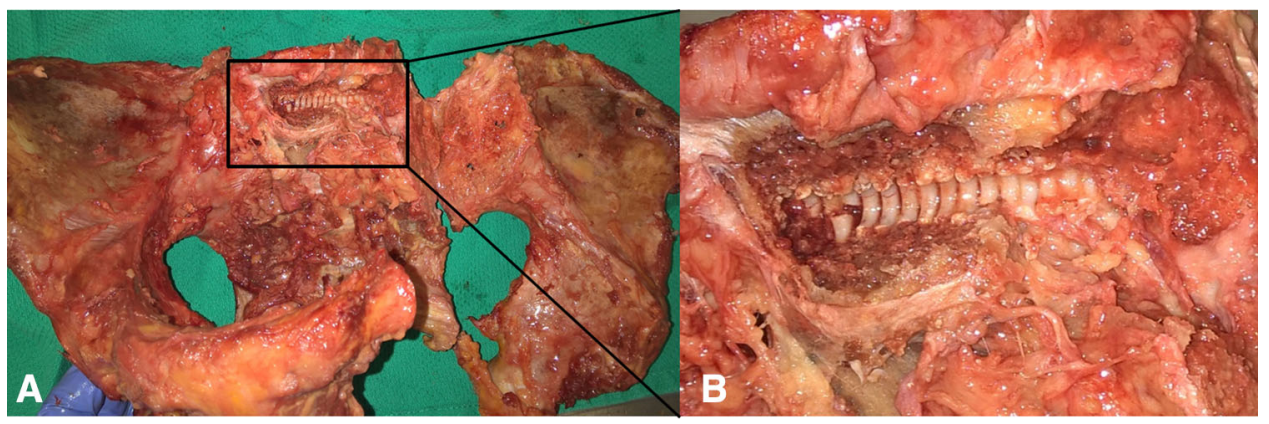

Fig. 1A-B (A) A pelvic specimen from the cemented group is shown after implant removal The intact posterior sacroiliac ligaments serve as a hinge behind the created fracture. (B) The anterior wall of S1 has been removed to show the cement envelope around the screw
(Original magnification, $\times 4$ ). The addition of cement increases the diameter of the screw and thereby limits the space between the implant and cortical borders of the sacrum.
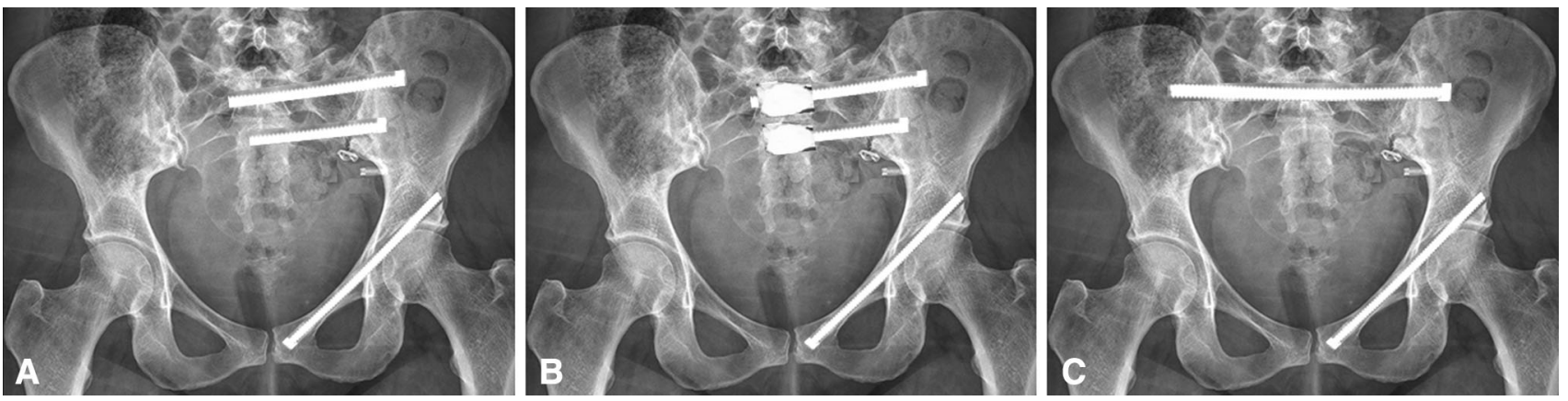

Fig. 2A-C The testing samples in the three groups are shown. (A) In the sacroiliac group, fixation was done by two standard sacroiliac screws in S1 and S2 and one intramedullary pubic ramus screw. (B) In the cemented group, the same configuration was used but with the

USA), a 64-slice scanner (Toshiba Aquilion ${ }^{\mathrm{TM}}$; Toshiba Corporation, Irvine, CA, USA) $(120 \mathrm{kVp}, 200 \mathrm{~mA} \times 0.5$ second rotation/100 mAs, $0.5-\mathrm{mm}$ slice thickness). Reformats were reconstructed from $0.5 \mathrm{~mm} / 0.3 \mathrm{~mm}$ volumes resulting in $0.5-\mathrm{mm}$ voxels. Hounsfield units were determined in regions of interest in the central trabecular bone of the body of S1 on axial $\left(3 \mathrm{~cm}^{2}\right)$ and sagittal $\left(1.5 \mathrm{~cm}^{2}\right)$ reconstructions and averaged. Using the phantom's reference values, median BMDs were calculated for all three testing groups (sacroiliac: $115 \mathrm{mg} / \mathrm{cm}^{3}$, range, $64-152 \mathrm{mg} /$ $\mathrm{cm}^{3}$; cemented: $81 \mathrm{mg} / \mathrm{cm}^{3}$, range, $32-193 \mathrm{mg} / \mathrm{cm}^{3}$; transsacral: $109 \mathrm{mg} / \mathrm{cm}^{3}$, range, $48-156 \mathrm{mg} / \mathrm{cm}^{3}$ ) [4]. With the numbers available, there were no differences in BMD among the three groups $(p=0.878)$, and all specimens had BMDs of less than half the values reported for $\mathrm{S} 1$ in young patients [22]. The CT scans also were used to measure screw lengths (S1, S2, and transsacral) and to identify the specimens that had no safe transsacral corridor [26]. Likewise, with the numbers available, there were no differences in virtual S1 transsacral screw size (distance of the ipsilateral ilium to the contralateral ilium through S1) among the groups (sacroiliac: $160 \mathrm{~mm}$, range, 150-165 addition of cement augmentation of the sacroiliac screws. (C) For the transsacral group, one single transsacral screw through S1 was combined with a pubic ramus screw.

$\mathrm{mm}$; cemented: $155 \mathrm{~mm}$, range, $150-180 \mathrm{~mm}$; transsacral: $150 \mathrm{~mm}$, range, $145-175 \mathrm{~mm})(\mathrm{p}=0.609)$.

After cement-augmented screw fixation and before biomechanical testing, the pelvic samples of the cemented group underwent a repeat CT scan to detect and assess cement leakage.

The experimental setup was designed to progressively provoke loosening or cutout of the screws by fatigue or damage accumulation in the area of the bone-implant interface. All samples underwent mechanical testing of a common setup simulating cyclic single-leg stance using a universal testing machine (ElectroPuls ${ }^{\mathrm{TM}}$ E10000 LinearTorsion; Instron ${ }^{\circledR}$, Norwood, MA, USA) (Fig. 3). Each specimen was subjected to consecutive cyclic loadings at 1 $\mathrm{Hz}$ (Fig. 4) beginning with a sinusoidal axial force from 100 to $250 \mathrm{~N}$ and $1.5 \mathrm{Nm}$ torque acting on the freely pivoting sacrum while the left acetabulum was able to move around a femoral head substitute [6] to simulate toetouch weightbearing. After 2500 cycles, the axial load was increased to $500 \mathrm{~N}$ to simulate walking on a walker (Videos 1, 2. Supplemental material is available with the online version of CORR ${ }^{\circledR}$ ) and after another 2500 cycles, it 


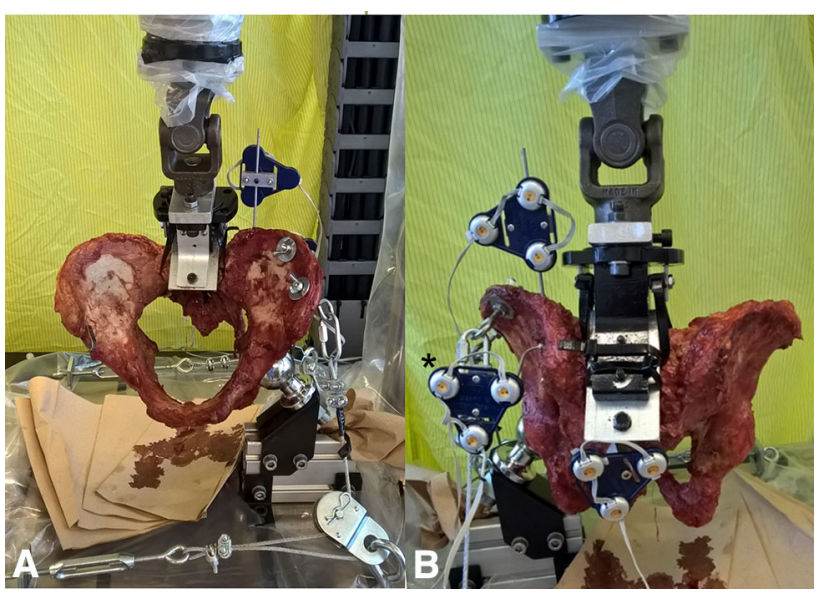

Fig. 3A-B (A) On a universal testing machine, cyclic loadings were applied through the sacrum that was allowed to pivot in all planes while the left hip socket articulated with a fixed femoral head substitute. Hip abductor muscles were simulated by cable pulleys attached to the iliac crest. (B) Displacement under loading was measured using an optoelectronic camera system. Markers were placed on the iliac crest, the sacrum, and the S1 screw (*).

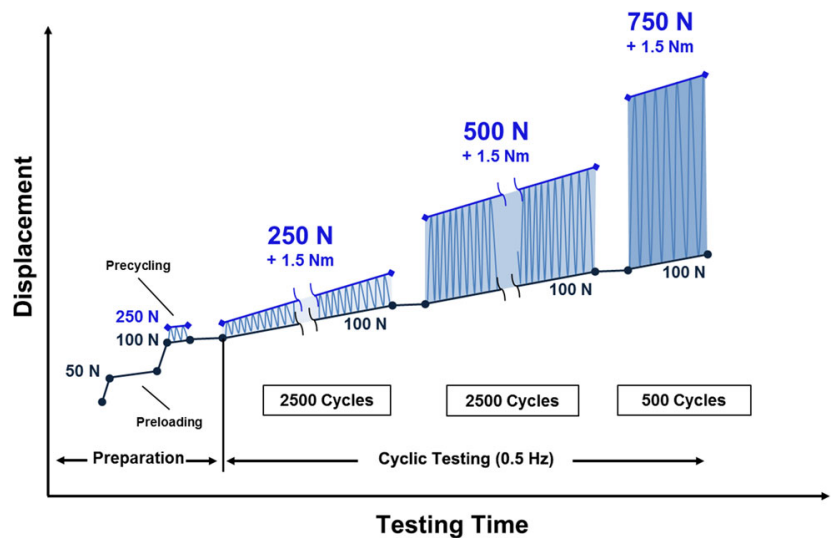

Fig. 4 The applied cyclic loading protocol is shown.

was increased to $750 \mathrm{~N}$ to simulate full weightbearing. Before testing, all specimens were preloaded with $50 \mathrm{~N}$ to balance tilt and rotation using the pulleys simulating the abductor and iliotibial band apparatus and then were precycled between $100 \mathrm{~N}$ and $250 \mathrm{~N}$ (five cycles) to level initial subsidence.

Axial displacement of the sacrum beyond $25 \mathrm{~mm}$ (after precycling) was determined as failure resulting in an immediate stop of testing to achieve an actual sacroiliac displacement beyond what would be considered failure of fixation. In case of implant loosening or cutout, the testing was continued until definitive failure occurred (as determined previously).

Motions of the sacrum in relation to the ilium and of the screw in relation to the sacrum and to the ilium were recorded during the whole testing by optoelectric motion

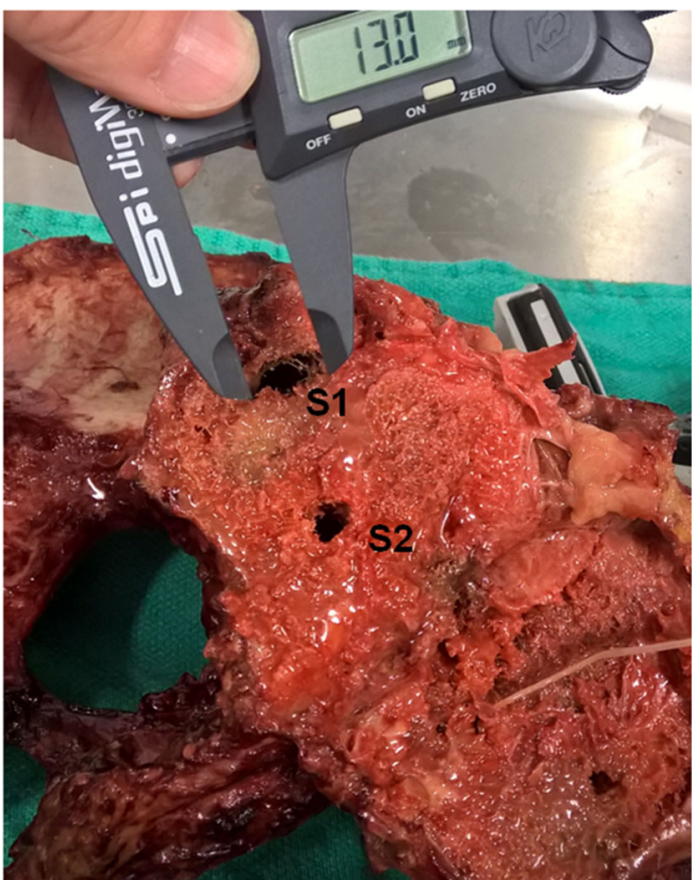

Fig. 5 To determine screw subsidence as an additional measure of screw loosening, the length of the medial-sided screw hole in S1 was quantified from inside the fracture after biomechanical testing. Screw subsidence was defined as the difference between maximum screw hole diameter and the core diameter of the screw.

tracking (Optotrak Certus ${ }^{\circledR}$; NDI, Waterloo, Ontario, Canada) (Fig. 3B).

The primary outcome parameter was the amount of screw loosening $(\mathrm{mm})$ measured by optoelectronically measured screw tip motion in relation to the sacrum during cyclic loading with $250 \mathrm{~N} / 1.5 \mathrm{Nm}$. This was defined as the maximal distance between the digitized tip of the screw in S1 and the center of the sacral body S1 (resulting vector of digitized points in the foramen of $\mathrm{S} 1$ and the base of the L5/S1 facet joints). This was confirmed by measuring the screw subsidence as an additional measure of screw loosening (Fig. 5). To determine screw subsidence, the length of the medial-sided screw hole in S1 was quantified from inside the fracture after the biomechanical testing using a caliper (Digimax Digital Caliper; Wiha Werkzeuge GmbH, Schonach, Germany) (device tolerance, $\pm 0.1 \mathrm{~mm}$ ). Screw subsidence was defined as the difference between maximum screw hole diameter and the core diameter of the screw $(4.8 \mathrm{~mm})$ [18].

The secondary outcome parameter was construct survival (n), defined as the number of cycles needed until failure (as defined in the mechanical testing section) occurred. Because a measure for the amount of energy absorbed until failure of the construct occurred, the median product of performed cycles and acting axial force was calculated and compared across the three groups. 
The tertiary outcome parameter was the amount of sacral fracture site motion $(\mathrm{mm})$, defined as the magnitude of translation of the sacrum relative to the ilium within one loading cycle measured every 500 cycles during loading with $250 \mathrm{~N} / 1.5 \mathrm{Nm}$. These data were determined every 100 cycles.

Additional outcome parameters were mode of failure and cement leakage by location and volume of cement leakage measured by a postinterventional CT scan of all specimens in the cemented group. Mode of failure was qualitatively assessed by video-documented observation of the samples' behavior under testing and until failure. Outlet pelvic fluoroscopy images (ARCADIS ${ }^{\circledR}$ Orbic 3D; Siemens Medical Solutions USA, Inc, Malvern, PA, USA) were taken with preloading, after 2500 and/or 5000 cycles of loading, and after failure in the loaded condition from each sample to support this evaluation and to achieve better understanding of how the constructs failed.

\section{Statistical Analysis}

The primary outcome was the amount of screw loosening. In previous clinical series, sacroiliac screw loosening was approximately $10 \%$ in mixed populations [31, 32]. As known from spine surgery, the risk of screw loosening in patients with osteoporosis can be as much as $25 \%$ [30, 47]. Thus, the presence of osteoporosis was estimated to double the rate of screw loosening, therefore we set the clinically relevant effect size in this model of osteoporosis as cement resulting in halving of the amount of screw migration. Assuming a SD of $\pm 5 \%$, a sample size calculation was performed using PS Power and Sample Size Calculation version $3.0(\alpha=0.05)$ [8]. The calculated number of samples required with a power of 0.8 was five per group.

Posttest analysis was done using SPSS for Windows Version 23.0 (IBM Corporation, Armonk, NY, USA) and MATLAB $^{\circledR}$ (MathWorks ${ }^{\circledR}$, Natick, MA, USA).

All data are reported as medians with the minimum and maximum value (range). Nonparametric tests were used to compare differences of medians across and between the three groups. The level of significance was defined as a probability less than 0.05 .

\section{Results}

Screw Loosening

The maximal median screw tip motion in relation to the sacrum during cyclic loading with $250 \mathrm{~N} / 1.5 \mathrm{Nm}$ was not different among the three groups with the numbers available, at $1.2 \mathrm{~mm}$ (range, $0.6-1.9 \mathrm{~mm}$ ) in the sacroiliac group, $0.7 \mathrm{~mm}$ (range, $0.5-1.3 \mathrm{~mm}$ ) in the cemented group, and $1.1 \mathrm{~mm}$ (range, $0.6-2.3 \mathrm{~mm}$ ) in the transsacral group $(p=0.940)$. However, screw subsidence measured in the medial-sided screw hole of the sacral fracture after implant removal was less in the cemented group $(3.0 \mathrm{~mm}$; range, $1.2-3.7 \mathrm{~mm}$ ) compared with the sacroiliac group $(5.7 \mathrm{~mm}$; range, $4.7-10.4 \mathrm{~mm})$, or the transsacral group $(5.6 \mathrm{~mm}$; range, $3.8-10.5 \mathrm{~mm})(\mathrm{p}=0.031)$.

\section{Construct Survival}

There was no difference with the numbers available in the median number of cycles needed until failure; this was 2921 cycles (range, 2586-5450 cycles) in the cemented group, 2570 cycles (range, 2500-5107 cycles) for the sacroiliac specimens, and 2578 cycles (range, 2540-2623 cycles) in the transsacral group ( $\mathrm{p}=0.153)$. The cemented group absorbed more energy before failure $\left(8.2 \times 10^{5}\right.$ $N^{*}$ cycles; range, $\left.6.6 \times 10^{5}-22.6 \times 10^{5}\right)$ compared with the transsacral group $\left(6.5 \times 10^{5} \mathrm{~N}^{*}\right.$ cycles, range, $6.4 \times 10^{5}-$ $\left.6.7 \times 10^{5}\right)(\mathrm{p}=0.016)$. All specimens survived the first 2500 cycles of cyclic loading with $250 \mathrm{~N} / 1.5 \mathrm{Nm}$. All transsacral specimens (five of five) failed within the subsequent first 30 cycles of loading with $500 \mathrm{~N} / 1.5 \mathrm{Nm}$. One (of five) specimen in the sacroiliac group and two (of five) specimens in the cemented group survived all 2500 cycles with $500 \mathrm{~N} / 1.5 \mathrm{Nm}$. The remaining sacroiliac specimen failed within 100 cycles, and the remaining cemented specimens within 450 cycles of loading with $750 \mathrm{~N} / 1.5 \mathrm{Nm}$ (Fig. 6).

\section{Sacral Fracture Site Motion}

With the numbers available, there was no difference among the three study groups in terms of fracture-site motion. The magnitude of translation of the sacrum relative to the ilium in one loading cycle measured every 500 cycles during loading with $250 \mathrm{~N} / 1.5 \mathrm{Nm}$ showed an increase with time in all groups. The maximal sacral fracture site motion was $2.9 \mathrm{~mm}$ (range, $0.7-5.4 \mathrm{~mm}$ ) in the sacroiliac group, 1.2 $\mathrm{mm}$ (range, $0.6-1.9 \mathrm{~mm}$ ) in the cemented group, and 2.1 $\mathrm{mm}$ (range, $1.2-4.8 \mathrm{~mm}$ ) in the transsacral group (across groups, $p=0.031$; between group comparisons, sacroiliac versus cemented: $p=0.206$, sacroiliac versus transsacral: $\mathrm{p}=1.0$, cemented versus transsacral: $\mathrm{p}=0.206$ ).

\section{Mode of Failure}

Regarding the qualitative analysis of the mode of failure, the sacral fracture always was seen to be the site of major 
Fig. 6 The results of construct survival are shown.

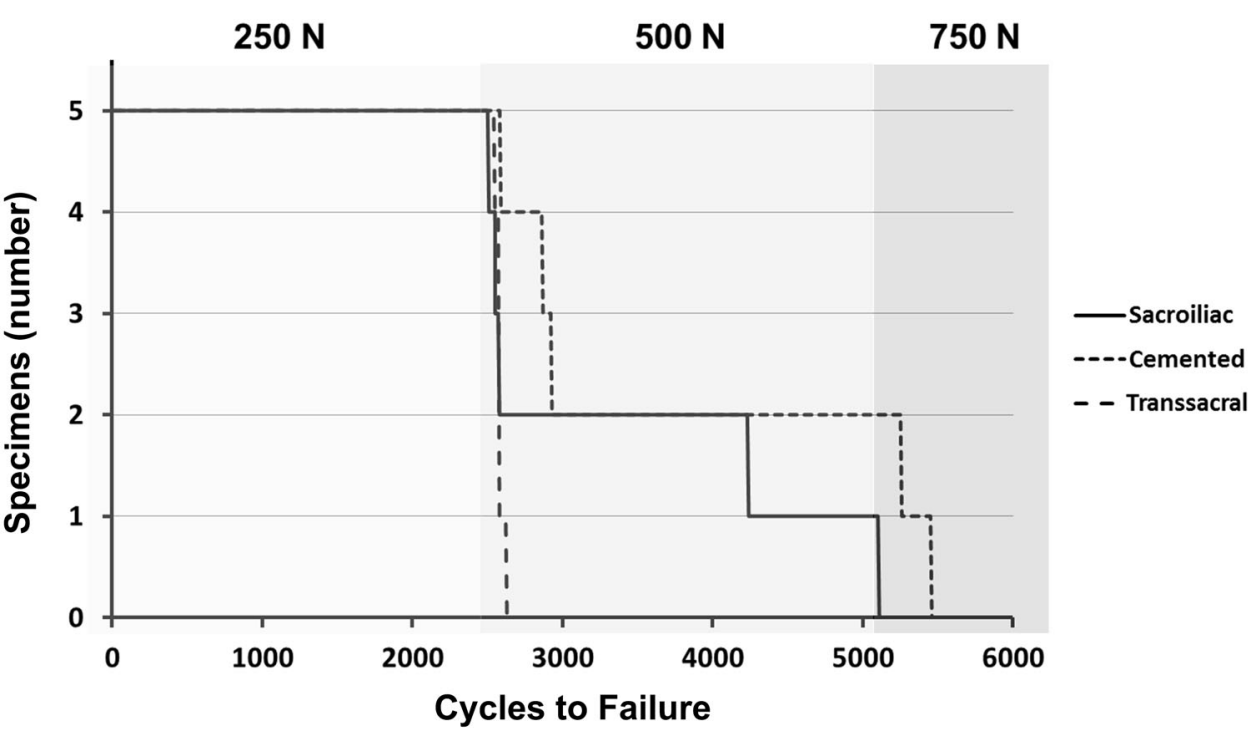

Fig. 7A-B Radiographic outlet views of a tested pelvis from the transsacral group are shown $(\mathbf{A})$ without loading and (B) under loading with $500 \mathrm{~N} / 1.5 \mathrm{Nm}$. The fully-threaded transsacral screws tended to bend under loading as soon as the screw started to interfere with the cortical borders of S1.
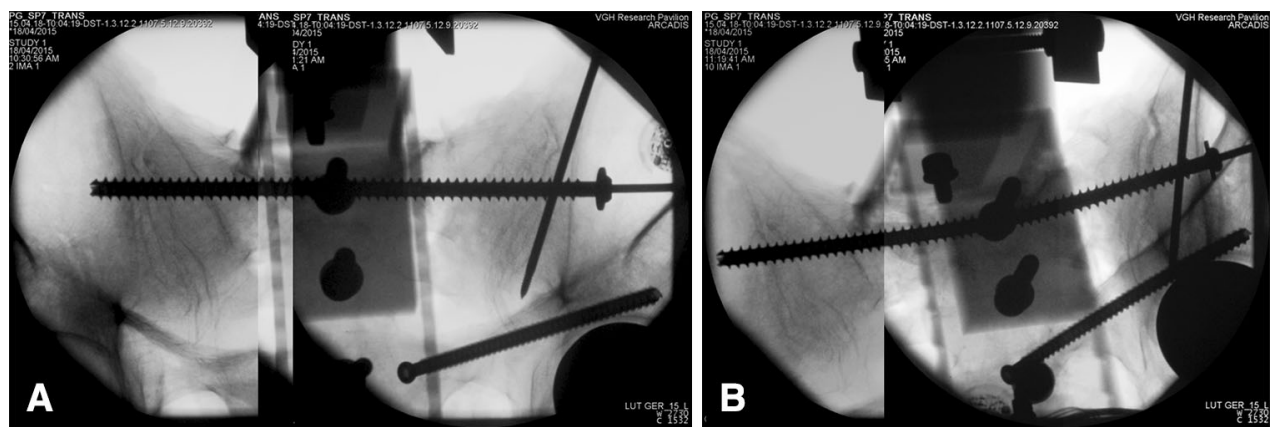

motion between the sacral body and ilium. The anterior pelvic ring showed only little motion at the stabilized pubic rami fracture but as a whole acted and deformed in a springlike manner. Anteroinferior pivoting and rotation of the sacrum around the axis of the screw in S1 was seen in all groups.

In the sacroiliac and cemented specimens, the sacrum initially moved independently from the screws and ilium. With more cycles being applied and increasing loosening of the screws, these came into contact with the surrounding cortical borders of the sacrum (anterior and posterior walls, sacral endplate, and the cortical borders defining the foramina). Consequently, the screws and ilium were pulled down together with the sacrum at this stage, also leading to loosening of the screw in relation to the ilium and finally resulting in failure.

In the transsacral specimens, initially independent movement of the sacrum around the screw also was seen. As soon as the screw started to interfere with the cortical borders of the body of $\mathrm{S} 1$, the screw began to undergo elastic and, to some part, plastic deformation (Fig. 7) and bending.
Cement Distribution

The postinterventional CT scan of the specimens in the cemented group showed a measurable cement mantle around all screws with a median length of $41 \mathrm{~mm}$ (range, $36-50 \mathrm{~mm}$ ) and width of $11 \mathrm{~mm}$ (range, $10-16 \mathrm{~mm}$ ). Small cement extrusions into the left $\mathrm{S} 1$ foramen were seen in three of five specimens, twice originating from the S2 screw canal (both $1 \times 1 \times 2 \mathrm{~mm}$ ) and once from the $\mathrm{S} 1$ screw canal $(2 \times 2 \times 5 \mathrm{~mm})$. In one case, minor leakage of the cement into the fracture was seen.

\section{Discussion}

Fragility fractures of the pelvis are an important clinical challenge. Affected patients frequently are of advanced age, they often present with impaired bone quality, and many have serious medical comorbidities. The primary goal in the treatment of these patients is early full weightbearing mobilization, which may be aided by surgical stabilization to decrease pain and facilitate mobility. 
Poor sacral fixation from screws that pull out of the osteopenic bone is a known technical challenge in this patient population. To compare several available alternatives that are in common clinical use, specifically with respect to their fixation strength, we sought to investigate in vitro the potential biomechanical benefit of cement augmentation in sacroiliac screw fixation. The underlying scientific question was whether cement augmentation in a cadaver model of osteoporotic bone improves the strength of the construct, specifically with respect to screw loosening, construct survival, and fracture-site motion.

A limitation of cadaver studies is the potential presence of confounding factors like bone quality and pelvic size. Although we found no differences among the groups regarding the median BMD and iliotranssacral width, other kinds of variability in each group, including the individual structural properties of each specimen, might have influenced the results, including some of the no-difference findings. The alternative would have been to use osteoporotic bone models with the advantage of similarity in material properties but the disadvantage that these properties differ from real bone. In vivo, screw migration is a combination of trabecular microfracturing and formation of fibrous tissue at the implant-bone interface owing to micromovements [3]. In vitro, the latter cannot be simulated; we believe that the biomechanical behavior of the trabecular structure of an osteoporotic cadaver pelvis is closer to reality than that of the homogeneous foams used in the plastic models.

We compared sacroiliac and cemented two-screw constructs with a transsacral one-screw construct. It is possible that it was only the combination of cement and two-screw construct that led to the small advantages seen in the cemented group. However, this represents the decisions made in clinical routine, where transsacral one-screw $[13,17,28]$ and sacroiliac two-screw fixation $[10,23,24,31,37,42]$ are common. In addition, transsacral two-screw constructs require the presence of a transsacral corridor in S1 and S2 (or one wide enough in S1), which is not present in approximately $30 \%$ of patients [27].

Unlike other studies [24, 40], we added anterior fixation with a retrograde transpubic screw [14] in all specimens. In the clinical context of an osteoporotic lateral compression fracture, the use of additional anterior fixation might be controversial; in the case of our cadaver model, the function of this anterior implant was to standardize and account for the missing soft tissues that usually stabilize the anterior pelvic ring. We do not expect that one of the three posterior constructs would have been favored by the addition of this screw. In addition, there is no standard in biomechanical testing of pelvic ring fractures. The setup and some of the loads applied in this study were chosen similar to those reported in published studies [24, 33, 39, 43]. In addition, a stepwise increase in loads $[12,40]$ was chosen to simulate the cyclic loading environment resulting from different levels of weightbearing (toe-touch, walking with a walker, full weightbearing) because they would be expected in the heterogeneous elderly population with fragility fractures of the pelvis with very different levels of balance, compliance, and pain.

We found that adding cement to the construct was somewhat helpful at mitigating screw loosening, although perhaps not as dramatically as we might have expected; there was no difference among the groups in terms of maximal screw-tip motion under cyclic loading, but median posttest screw subsidence favored the cemented group. Even though the number of cycles needed to provoke failure of the constructs was not different among the three groups, the energy absorbed was greater in the cemented than in the transsacral group. Other biomechanical studies using cyclic loading protocols have shown comparable results with improved implant anchorage in osteoporotic bone in the distal radius [18], proximal humerus [35], the proximal [11] and distal femur [44], and the spine [9]. Grechenig et al. [16] recently reported higher pullout forces of sacroiliac screws after cement augmentation, even though pullout strength may not be a well-chosen parameter for assessment of construct stability after pelvic fracture stabilization.

Postoperative implant loosening and pelvic ring displacement frequently are not a result of a single trauma or loading but occur secondary to repetitive motion (ie, ambulation). Therefore, we used a cyclic loading protocol, because this seems to best approximate the clinical loading scenario. Preliminary clinical studies showed a decrease in implant loosening rates with cement augmentation in the osteoporotic proximal femur [20] and spine [38]. Cement augmentation of sacroiliac screw fixation has been reported in small case reports and series [41, 46], and few complications were reported.

Finally, in our study although the cement was not injected under fluoroscopic control, the observed leakage (although minimal) in the neuroforamina and the fracture is of concern and should be considered when weighing the biomechanical benefit of such cement augmentation against its potential risks. : Slow cement application to decrease the intraosseous pressure [1], waiting for optimal viscosity of the cement [29], and use of intraoperative fluoroscopy during cement injection have been used to reduce complications associated with cement leakage in other regions of the body where intraosseous cementing is performed (such as vertebroplasty); these techniques might be worth considering to add a margin of safety during pelvic screw augmentation. 
Considering the separate findings of this study together, it seems that overall the weak spot of any fixation construct in the osteoporotic posterior pelvic ring is the body of S1. Failure occurs as rotation and pivoting of the sacral body around the implant. Two posterior screws seem to resist this motion better than one screw, even if it is a transsacral screw. The addition of cement virtually increases the diameter of the implant approximately 4 to $5 \mathrm{~mm}$ (Fig. 1), thereby limiting the space between the implant and cortical borders of the sacrum, and consequently alters the dynamics of failure and improves construct survival. Future studies will have to address if the same effect could be achieved by simply choosing wider implants and if the risks associated with a larger screw diameter outweigh those associated with cement augmentation.

In view of the small body of work on this topic to date, the addition of cement to standard sacroiliac screw fixation appears to alter the mode and dynamics of failure in this cadaveric model. In this small study, we observed no advantages to cement in terms of screw motion or cycles to failure among the constructs we tested. However, a cemented, two-screw sacroiliac screw construct resulted in less screw subsidence and greater energy absorbed to failure than an uncemented single transsacral screw. In osteoporotic bone, the addition of cement to sacroiliac screw fixation may have a positive effect on screw anchorage. Larger mechanical studies using these findings as pilot data and investigating the role of screw size and the number of screws inserted are needed before these preliminary findings can be applied clinically. First, clinical case series with carefully selected patients will have to prove the safety of cement augmentation in the sacrum. After this, larger clinical trials can be done to determine whether the potential biomechanical advantages of cemented sacroiliac screw fixation translate into clinical superiority of this technique.

Acknowledgments We thank Mike Brenneman (Centre for Hip Health and Mobility, Vancouver, Canada), for technical support with biomechanical testing, and Boris Sobolev MSc, PhD (Centre for Clinical Epidemiology and Evaluation, University of British Columbia, Vancouver, Canada), for counseling regarding the statistical analysis.

\section{References}

1. Blankstein M, Widmer D, Gotzen M, Hofmann-Fliri L, Richards RG, Gueorguiev B, Windolf M. Assessment of intraosseous femoral head pressures during cement augmentation of the perforated proximal femur nail antirotation blade. J Orthop Trauma. 2014;28:398-402.

2. Bruce B, Reilly M, Sims S. OTA highlight paper predicting future displacement of nonoperatively managed lateral compression sacral fractures: can it be done? J Orthop Trauma. 2011;25:523-527.
3. Cameron HU, Pilliar RM, MacNab I. The effect of movement on the bonding of porous metal to bone. J Biomed Mater Res. 1973;7:301-311.

4. Cann CE, Genant HK. Precise measurement of vertebral mineral content using computed tomography. J Comput Assist Tomogr. 1980;4:493-500.

5. Comstock CP, van der Meulen MC, Goodman SB. Biomechanical comparison of posterior internal fixation techniques for unstable pelvic fractures. J Orthop Trauma. 1996;10:517-522.

6. Damm P, Schwachmeyer V, Dymke J, Bender A Bergmann G. In vivo hip joint loads during three methods of walking with forearm crutches. Clin Biomech (Bristol, Avon). 2013;28:530-535.

7. Dattani R, Krykorka P, Guy P. Low energy pelvic ring injuries. In Hak DJ, Ipaktchi KR, Morgan SJ, eds. Orthopedic Trauma Call for the Attending Surgeon. Thorofare, NJ: Slack Inc. 2012:285292.

8. Dupont WD, Plummer WD Jr. Power and sample size calculations for studies involving linear regression. Control Clin Trials. 1998;19:589-601.

9. Elder BD, Lo SF, Holmes C, Goodwin CR, Kosztowski TA, Lina IA, Locke JE, Witham TF. The biomechanics of pedicle screw augmentation with cement. Spine J. 2015;15:1432-1445.

10. Farrell ED, Gardner MJ, Krieg JC, Chip Routt ML Jr. The upper sacral nerve root tunnel: an anatomic and clinical study. J Orthop Trauma . 2009;23:333-339.

11. Fensky F, Nuchtern JV, Kolb JP, Huber S, Rupprecht M, Jauch SY, Sellenschloh K, Puschel K, Morlock MM, Rueger JM, Lehmann W. Cement augmentation of the proximal femoral nail antirotation for the treatment of osteoporotic pertrochanteric fractures: a biomechanical cadaver study. Injury. 2013;44:802807.

12. Ferguson SJ, Winkler F, Nolte LP. Anterior fixation in the osteoporotic spine: cut-out and pullout characteristics of implants. Eur Spine J. 2002;11:527-534.

13. Fox J, Sanders D, Starr A, Sathy A, John C. Transsacral-transiliac screw stabilization: effective for recalcitrant pain due to sacral insufficiency fracture. J Orthop Trauma. 2016 April 28. [Epub ahead of print] doi: 10.1097/BOT.0000000000000596.

14. Gansslen A, Krettek C. Retrograde transpubic screw fixation of transpubic instabilities. Oper Orthop Traumatol. 2006;18:330340.

15. Gardner MJ, Routt ML Jr. Transiliac-transsacral screws for posterior pelvic stabilization. J Orthop Trauma. 2011;25:378384.

16. Grechenig S, Gansslen A, Gueorguiev B, Berner A, Muller M, Nerlich M Schmitz P. PMMA-augmented SI screw: a biomechanical analysis of stiffness and pull-out force in a matched paired human cadaveric model. Injury. 2015; 46(suppl 4):S125128.

17. Heydemann J, Hartline B, Gibson ME, Ambrose CG, Munz JW, Galpin M, Achor TS, Gary JL. Do transsacral-transiliac screws across uninjured sacroiliac joints affect pain and functional outcomes in trauma patients? Clin Orthop Relat Res. 2016;474:1417-1421.

18. Hogel F, Mair S, Eberle S, Weninger P, von Oldenburg G, Augat P. Distal radius fracture fixation with volar locking plates and additional bone augmentation in osteoporotic bone: a biomechanical study in a cadaveric model. Arch Orthop Trauma Surg. 2013;133:51-57.

19. Hutchinson GS, Griffon DJ, Siegel AM, Pijanowski GJ, Kurath P, Eurell JA, Johnson AL. Evaluation of an osteoconductive resorbable calcium phosphate cement and polymethylmethacrylate for augmentation of orthopedic screws in the pelvis of canine cadavers. Am J Vet Res. 2005;66:1954-1960.

20. Kammerlander C, Doshi H, Gebhard F, Scola A, Meier C, Linhart W, Garcia-Alonso M, Nistal J, Blauth M. Long-term results of the 
augmented PFNA: a prospective multicenter trial. Arch Orthop Trauma Surg. 2014;134:343-349.

21. Kennedy J, Molony D, Burke NG, FitzPatrick D, Mullett H. Effect of calcium triphosphate cement on proximal humeral fracture osteosynthesis: a cadaveric biomechanical study. $J$ Orthop Surg (Hong Kong). 2013;21:173-177.

22. Lu WW, Zheng Y, Holmes A, Zhu Q, Luk KD, Zhong S Leong JC. Bone mineral density variations along the lumbosacral spine. Clin Orthop Relat Res. 2000;378:255-263.

23. Matta JM. Indications for anterior fixation of pelvic fractures. Clin Orthop Relat Res. 1996;329:88-96.

24. Mears SC, Sutter EG, Wall SJ, Rose DM, Belkoff SM. Biomechanical comparison of three methods of sacral fracture fixation in osteoporotic bone. Spine (Phila Pa 1976). 2010;35:E392-395.

25. Mehling I, Hessmann MH, Rommens PM. Stabilization of fatigue fractures of the dorsal pelvis with a trans-sacral bar: operative technique and outcome. Injury. 2012;43:446-451.

26. Mendel T, Noser H, Kuervers J, Goehre F, Hofmann GO, Radetzki F. The influence of sacral morphology on the existence of secure S1 and S2 transverse bone corridors for iliosacroiliac screw fixation. Injury. 2013;44:1773-1779.

27. Mendel T, Noser H, Wohlrab D, Stock K, Radetzki F. The lateral sacral triangle: a decision support for secure transverse sacroiliac screw insertion. Injury. 2011;42:1164-1170.

28. Moed BR, Whiting DR. Locked transsacral screw fixation of bilateral injuries of the posterior pelvic ring: initial clinical series. J Orthop Trauma. 2010;24:616-621.

29. Nieuwenhuijse MJ, Muijs SP, van Erkel AR, Dijkstra SP. A clinical comparative study on low versus medium viscosity polymethylmetacrylate bone cement in percutaneous vertebroplasty: viscosity associated with cement leakage. Spine (Phila Pa 1976). 2010;35:E1037-1044.

30. Ohtori S, Inoue G, Orita S, Yamauchi K, Eguchi Y, Ochiai N, Kishida S, Kuniyoshi K, Aoki Y, Nakamura J, Ishikawa T, Miyagi M, Kamoda H, Suzuki M, Kubota G, Sakuma Y, Oikawa Y, Inage K, Sainoh T, Takaso M, Toyone T, Takahashi K. Comparison of teriparatide and bisphosphonate treatment to reduce pedicle screw loosening after lumbar spinal fusion surgery in postmenopausal women with osteoporosis from a bone quality perspective. Spine (Phila Pa 1976). 2013;38:E487-492.

31. Osterhoff G, Ossendorf C, Wanner GA, Simmen HP, Werner CM. Percutaneous iliosacral screw fixation in S1 and S2 for posterior pelvic ring injuries: technique and perioperative complications. Arch Orthop Trauma Surg. 2011;131:809-813.

32. Osterhoff G, Ossendorf C, Wanner GA, Simmen HP, Werner CM. Posterior screw fixation in rotationally unstable pelvic ring injuries. Injury. 2011;42:992-996.

33. Osterhoff G, Tiziani S, Hafner C, Ferguson SJ, Simmen HP, Werner CM. Symphyseal internal rod fixation versus standard plate fixation for open book pelvic ring injuries: a biomechanical study. Eur J Trauma Emerg Surg. 2016;42:197-202.

34. Papakostidis C, Kanakaris NK, Kontakis G, Giannoudis PV. Pelvic ring disruptions: treatment modalities and analysis of outcomes. Int Orthop. 2009;33:329-338.
35. Roderer G, Scola A, Schmolz W, Gebhard F, Windolf M, Hofmann-Fliri L. Biomechanical in vitro assessment of screw augmentation in locked plating of proximal humerus fractures. Injury. 2013;44:1327-1332.

36. Rommens PM. Internal fixation in postpartum symphysis pubis rupture: report of three cases. J Orthop Trauma. 1997;11:273276.

37. Routt ML Jr. Posterior pelvic ring disruptions: iliosacral screws. In Wiss DA, Capers CM, Williams CB, eds. Master Techniques In Orthopaedic Surgery: Fractures. Philadelphia, PA: Lippincott Williams \& Wilkins; 2006: 649-667.

38. Sawakami K, Yamazaki A, Ishikawa S, Ito T, Watanabe K, Endo N. Polymethylmethacrylate augmentation of pedicle screws increases the initial fixation in osteoporotic spine patients. $J$ Spinal Disord Tech. 2012;25:E28-35.

39. Schildhauer TA, Josten C, Muhr G. Triangular osteosynthesis of vertically unstable sacrum fractures: a new concept allowing early weight-bearing. J OrthopTrauma. 2006;20(1 suppl):S4451.

40. Tabaie SA, Bledsoe JG, Moed BR. Biomechanical comparison of standard iliosacral screw fixation to transsacral locked screw fixation in a type C zone II pelvic fracture model. J Orthop Trauma. 2013;27:521-526.

41. Tjardes T, Paffrath T, Baethis H, Shafizadeh S, Steinhausen E, Steinbuechel T, Rixen D, Bouillon B. Computer assisted percutaneous placement of augmented iliosacral screws: a reasonable alternative to sacroplasty. Spine (Phila Pa 1976). 2008;33:14971500 .

42. Tsiridis E, Upadhyay N, Gamie Z Giannoudis PV. Percutaneous screw fixation for sacral insufficiency fractures: a review of three cases. J Bone Joint Surg Br. 2007;89:1650-1653.

43. Vigdorchik JM, Esquivel AO, Jin X, Yang KH, Onwudiwe NA, Vaidya R. Biomechanical stability of a supra-acetabular pedicle screw internal fixation device (INFIX) vs external fixation and plates for vertically unstable pelvic fractures. J Orthop Surg Res. 2012;7:31.

44. Wahnert D, Hofmann-Fliri L, Richards RG, Gueorguiev B, Raschke MJ, Windolf M. Implant augmentation: adding bone cement to improve the treatment of osteoporotic distal femur fractures: a biomechanical study using human cadaver bones. Medicine (Baltimore). 2014;93:e166.

45. Wahnert D, Hofmann-Fliri L, Schwieger K, Brianza S, Raschke MJ, Windolf M. Cement augmentation of lag screws: an investigation on biomechanical advantages. Arch Orthop Trauma Surg. 2013;133:373-379.

46. Wahnert D, Raschke MJ, Fuchs T. Cement augmentation of the navigated iliosacral screw in the treatment of insufficiency fractures of the sacrum: a new method using modified implants. Int Orthop. 2013;37:1147-1150.

47. Wu ZX, Gong FT, Liu L, Ma ZS, Zhang Y, Zhao X, Yang M, Lei W, Sang HX. A comparative study on screw loosening in osteoporotic lumbar spine fusion between expandable and conventional pedicle screws. Arch Orthop Trauma Surg. 2012;132: 471-476. 